\title{
Strategies for $x$-ray analysis of non-conductive specimens in a conventional scanning electron microscope
}

\author{
P.J.Statham
}

Oxford Instruments Analytical Limited, High Wycombe, Bucks HP12 3SE, U.K.

Identification (ID) of major elements within a small feature is a key requirement in forensic science, failure analysis and phase ID. Fig. 1 exemplifies the problem with non-conductive samples. The accumulated trapped charge raises surface potential, reducing the landing energy for electrons; the Duanne Hunt Limit, (DHL) is lowered well below $20 \mathrm{keV}$ and useful lines such as GaK are not excited. Furthermore, the surface field can deflect incident electrons away from the intended analysis spot and spurious peaks such as AlK give a false positive ID. If the specimen surface is irregular, carbon coating the specimen may not be effective because isolated islands of coated material still charge up. Such areas can be identified by mapping the intensity of $x$-rays in a band just below the DHL. In fig. 3(b) the x-ray map identifies areas in the corresponding s.e. image 3(a) that are still charging despite the conductive coating. Fig.3(c) shows two spectra integrated from spectrum image pixels within the boxed areas in fig.3(a). Where coating is not an option, variable pressure SEM provides one route to neutralise surface charge. However, the beam "skirt" may excite elements well outside the analysed feature and give false IDs. Alternatively, in conventional $\mathrm{SEM}$, reducing beam $\mathrm{kV}$ increases the current fractions lost by secondary emission and backscatter. As shown in fig. 4 , for the same beam current, the specimen will retain $60 \%$ less current at $5 \mathrm{kV}$ than at $20 \mathrm{kV}$. This helps imaging but element ID is more difficult because of the greater loss of $\mathrm{x}$-ray excitation. A more effective strategy is to tilt the sample. As fig.5 shows, while x-ray excitation falls off significantly at tilts beyond 30 degrees, the absorbed current fraction falls much more rapidly and at tilts of 70 degrees or more, charging may even be avoided if the absorbed fraction goes negative beyond the "E2" threshold. If the E2 limit cannot be achieved, landing energy will drop until increased emission and surface leakage is sufficient to neutralise residual current [1]. If charge does accumulate then analysis has to be completed before the surface potential begins to interfere with the beam [2]. 100pA for 10 seconds with a 6 msterad solid angle typically gives enough x-rays for qualitative ID and increasing solid angle reduces necessary current. Fig. 2 shows an idealised electrostatic model for the effects of trapped charge. Rastering the beam will not alter the $\mathrm{x}$-ray acquisition rate but by spreading the dose over a larger area, the rise in surface potential (drop in DHL) is slowed down by $1 / R$. If the sample is thin enough so that $d \approx R$, the potential is also suppressed by the grounded stub. (Alternatively, a ground plane on the sample surface surrounding the uncoated area reduces the magnitude of the surface potential for a given Q.) A charged sample can be discharged by slowly ramping down the $\mathrm{kV}$ so that the landing energy on all charged areas is always $<\mathrm{E} 2$. Below $1.5 \mathrm{kV}$, the specimen can then be imaged and new areas for analysis selected before the beam $\mathrm{kV}$ is restored. In a practical example at $7 \mathrm{kV}, 300 \mathrm{pA}$, an uncoated $\mathrm{Ba}_{2} \mathrm{TiSi}_{2} \mathrm{O}_{8}$ specimen charged immediately at normal incidence. At 55 deg.tilt in spot mode, 30 seconds acquisition with a $5 \mathrm{msterad}$ collection angle was achieved before DHL dropped by $0.5 \mathrm{keV}$. With a $10 \mathrm{um}$ raster width, analysis time extended to 480 seconds for the same effect.

[1] S. Fakhfakh et al, Nucl.Instr.and Meth. B 197 (2002), 114

[2] D.E.Newbury, Scanning 22, (2000), 345

[3] The assistance of Steve Pitman and Jenny Goulden in experiments is gratefully acknowledged. 

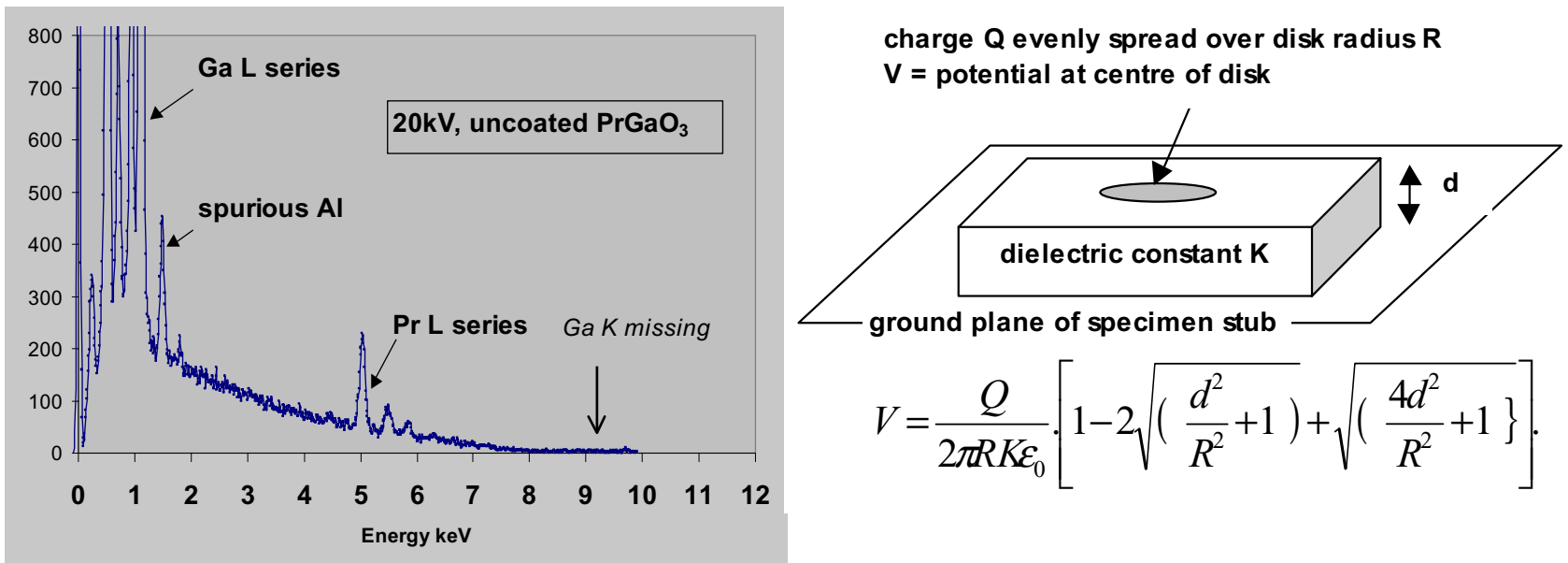

FIG 1: Element ID on charging sample
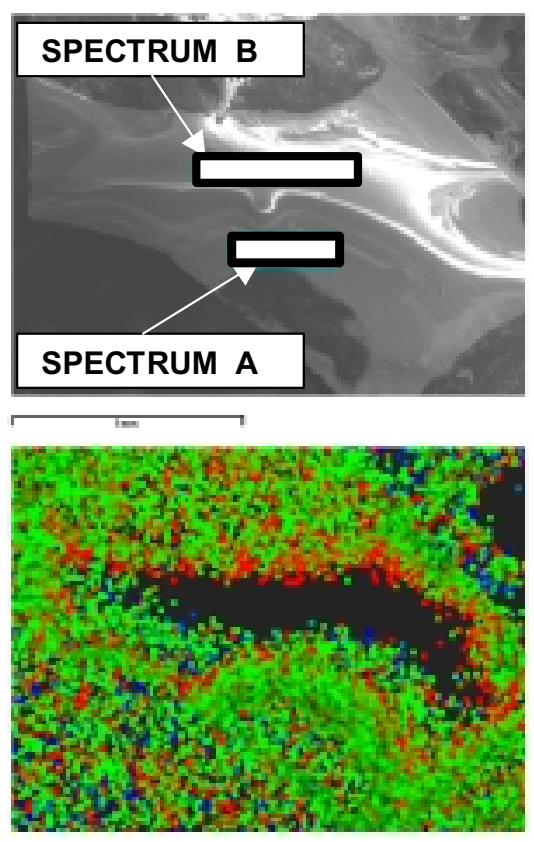

3(a)

3(b)
FIG 2: Idealised model of trapped charge

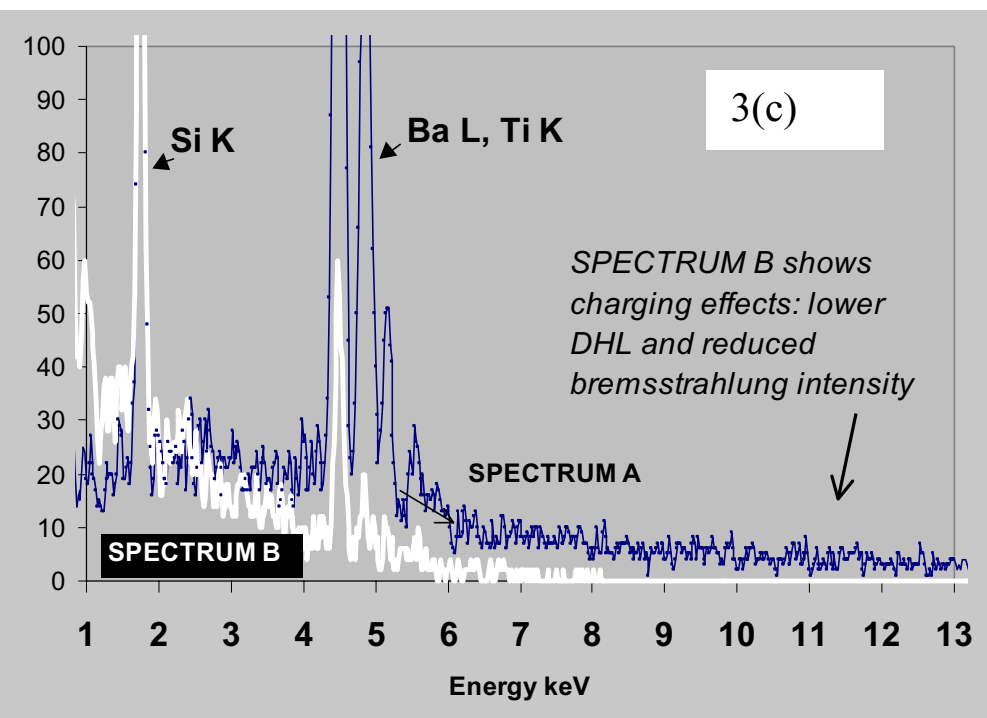

FIG 3: Coated $\mathrm{Ba}_{2} \mathrm{TiSi}_{2} \mathrm{O}_{8}$ at $20 \mathrm{kV}$ (a) s.e. image $2 \mathrm{~mm}$ field (b) $\mathrm{x}$-ray map for $10 \mathrm{keV}-20 \mathrm{keV}$ (c) spectra for regions in (a)

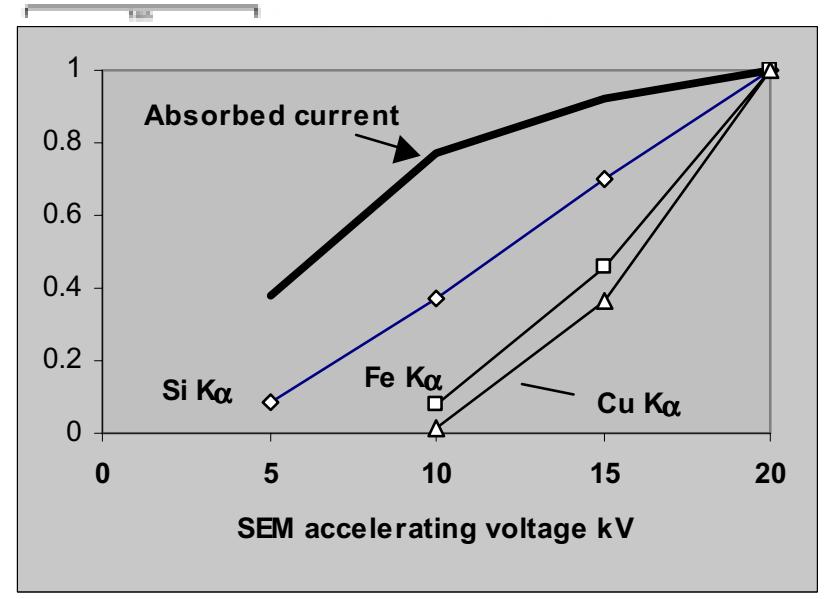

FIG 4: Excitation and dose relative to $20 \mathrm{kV}$ for fixed beam current at normal incidence

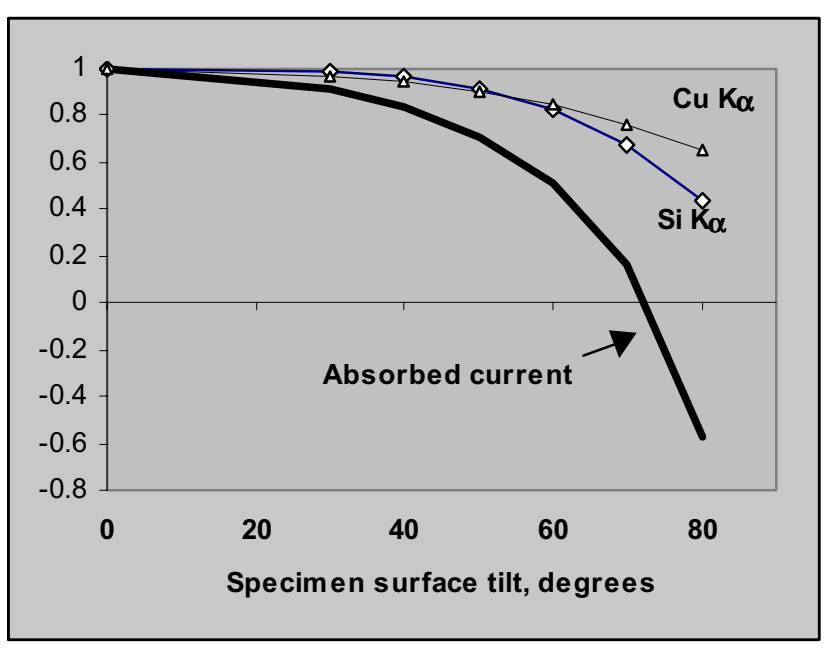

FIG 5: Effect of tilt for typical sample at $20 \mathrm{kV}$ 